\title{
Mapping Longitudinal Development of Local Cortical Gyrification in Infants from Birth to 2 Years of Age
}

\author{
Gang Li, ${ }^{1}$ Li Wang, ${ }^{1}$ Feng Shi, ${ }^{1}$ Amanda E. Lyall, ${ }^{2}$ Weili Lin, ${ }^{1}$ John H. Gilmore, ${ }^{2}$ and Dinggang Shen ${ }^{1,3}$ \\ ${ }^{1}$ Department of Radiology and Biomedical Imaging and Research Center, ${ }^{2}$ Department of Psychiatry, University of North Carolina at Chapel Hill, North \\ Carolina 27599, and ${ }^{3}$ Department of Brain and Cognitive Engineering, Korea University, Seoul 136-713, Korea
}

Human cortical folding is believed to correlate with cognitive functions. This likely correlation may have something to do with why abnormalities of cortical folding have been found in many neurodevelopmental disorders. However, little is known about how cortical gyrification, the cortical folding process, develops in the first 2 years of life, a period of dynamic and regionally heterogeneous cortex growth. In this article, we show how we developed a novel infant-specific method for mapping longitudinal development of local cortical gyrification in infants. By using this method, via 219 longitudinal 3T magnetic resonance imaging scans from 73 healthy infants, we systemically and quantitatively characterized for the first time the longitudinal cortical global gyrification index (GI) and local GI (LGI) development in the first 2 years of life. We found that the cortical GI had age-related and marked development, with $16.1 \%$ increase in the first year and 6.6\% increase in the second year. We also found marked and regionally heterogeneous cortical LGI development in the first 2 years of life, with the high-growth regions located in the association cortex, whereas the low-growth regions located in sensorimotor, auditory, and visual cortices. Meanwhile, we also showed that LGI growth in most cortical regions was positively correlated with the brain volume growth, which is particularly significant in the prefrontal cortex in the first year. In addition, we observed gender differences in both cortical GIs and LGIs in the first 2 years, with the males having larger GIs than females at 2 years of age. This study provides valuable information on normal cortical folding development in infancy and early childhood.

Key words: cortical folding; cortical surface; infant; local gyrification; longitudinal development

\section{Introduction}

The human cerebral cortex is a highly convoluted structure composed of concave sulci and convex gyri (Ono et al., 1990). Gyrification, the convoluted cortical folding process, is a consequence of dynamic brain growth during embryonic and early postnatal development (Zilles et al., 1989). During the third trimester of fetal life, the human brain grows dramatically from a relatively smooth, lissencephalic structure into a convoluted structure, resembling the morphology of the adult brain (Armstrong et al., 1995). Gyrification allows for a drastic increase of the cortical surface area in relation to the brain skull. This enables the cortex to accommodate a greater number of neurons (White et al., 2010).

To measure the cortical folding degree, the gyrification index (GI), originally developed for 2D brain slices (Zilles et al., 1988), is defined as the area ratio between the outer cortical surface and the cerebral hull surface tightly wrapping the brain, recon-

Received Sept. 17, 2013; revised Jan. 23, 2014; accepted Feb. 13, 2014.

Author contributions: G.L., W.L., J.H.G., and D.S. designed research; G.L. and D.S. performed research; G.L., L.W., F.S., W.L., J.H.G., and D.S. contributed unpublished reagents/analytic tools; G.L., L.W., F.S., and D.S. analyzed data; G.L., A.E.L., J.H.G., and D.S. wrote the paper.

This work was supported in part by the National Institutes of Health (Grants EB006733, EB008760, EB008374, EB009634, MH088520, NS055754, HD053000, AG041721, MH064065, MH070890, and MH100217).

The authors declare no competing financial interests.

Correspondence should be addressed to Dinggang Shen, Radiology and BRIC, UNC-CH School of Medicine, MRI Building, CB \#7513, 106 Mason Farm Road, Chapel Hill, NC 27599. E-mail: dgshen@med.unc.edu.

DOI:10.1523/JNEUROSCI.3976-13.2014

Copyright $\odot 2014$ the authors $\quad 0270-6474 / 14 / 334228-11 \$ 15.00 / 0$ structed from 3D magnetic resonance (MR) images (Van Essen and Drury, 1997). Given the regional variations of the cortical folding, methods for measuring cortical local gyrification have also been proposed (Schaer et al., 2008; Toro et al., 2008; Lebed et al., 2013) to characterize the localized changes of the cortical folding during brain development, aging, and disorders. MR imaging studies have found that global and regional cortical GIs correlate with age (Raznahan et al., 2011), gender (Rogers et al., 2010), and cognitive functions (Luders et al., 2008). However, existing studies of cortical GI development are limited to schoolage children and adolescents (Raznahan et al., 2011; Shaw et al., 2012), whose GIs change little from year to year. Cortical folding during early postnatal development is an important early marker of later neurobehavioral development (Zilles et al., 2013). To date, the longitudinal development of cortical gyrification in early postnatal stages remains largely unknown, especially in the first years of life, an exceptionally dynamic period of brain structural and functional development (Fan et al., 2011; Nie et al., 2012). Studying the cortical gyrification development during these stages would provide valuable information for understanding the driving forces behind cortical folding and important insights into neurodevelopmental disorders that exhibit abnormal cortical gyrification (Zilles et al., 2013).

This study aims to quantitatively characterize both the global and local cortical gyrification developmental trajectories in the first 2 years of life. To study local gyrification development, we have to develop a novel method to deal with the issue of dynamic 
Table 1. Demographic information of the infant cohort

\begin{tabular}{llll}
\hline & All & Male & Female \\
\hline Subject & 73 & 42 & 31 \\
$\quad 30$ & 20 & 10 \\
$\quad$ ingleton & 43 & 22 & 21 \\
Age at neonatal MRI (days) & $25.5 \pm 10.8$ & $27.3 \pm 13.1$ & $23.0 \pm 6.1$ \\
Age at year 1 MRI (days) & $392.8 \pm 22.1$ & $390.0 \pm 21.6$ & $396.6 \pm 22.4$ \\
Age at year 2 MRI (days) & $758.1 \pm 38.1$ & $765.4 \pm 37.4$ & $748.2 \pm 37.4$ \\
\hline
\end{tabular}

cortex growth during these stages. Existing methods for measuring cortical local gyrification were designed for adolescent/adult studies (Schaer et al., 2008; Toro et al., 2008). Thus they do not take into account the dramatic changes in size among early developing brains and are not suitable for this study. Using our method, we systematically characterized for the first time several important features of the longitudinal cortical global and local gyrification development in the first 2 years, including the agerelated high-growth and low-growth regions of cortical local gyrification, as well as their correlations with brain volume growth.

\section{Materials and Methods}

Subjects. The Institutional Review Board of the University of North Carolina (UNC) School of Medicine approved this study. Pregnant mothers were recruited during the second trimester of pregnancy from the UNC hospitals. Informed consents were obtained from both parents. Exclusion criteria included abnormalities on fetal ultrasound and major medical or psychotic illness in the mother. Infants in the study cohort were free of congenital anomalies, metabolic disease, and focal lesions. Before scanning, infants were fed, swaddled, and fitted with ear protection. All infants were scanned unsedated (Gilmore et al., 2012).

The complete sets of longitudinal 0,1 , and 2 year scans were acquired for 73 normal infants. The study group includes 30 singletons (20 males/10 females) and 43 twins ( 22 males/21 females; 7 monozygotic twin pairs, 10 dizygotic pairs, and 8 "single" twins, babies whose twin brother or sister were not included in the study). Ethnic composition was 49 Caucasian, 23 African-American, and 1 Asian-American (Gilmore et al., 2012). At all three scanning ages, no significant age difference between males and females has been found (Li et al., 2013a). These subjects were part of a large prospective study of early brain development in healthy children (Knickmeyer et al., 2008; Gilmore et al., 2012). Our current success rate for obtaining usable MRIs is approximately as follows: $90 \%$ for neonate, $66 \%$ for 1 -year-old, and $60 \%$ for 2 -year-old. These subjects have been used in prior studies on the longitudinal development of regional cortical gray matter volume (Gilmore et al., 2012) and vertex-wise cortical surface area expansion (Li et al., 2013b). Demographic information of the infant cohort can be found in Table 1.

$M R$ image acquisition. Images were acquired on a Siemens head-only 3T scanner (Allegra, Siemens Medical Systems) with a circular polarized head coil. T1-weighted images (160 sagittal slices) were obtained by using the 3D magnetization-prepared rapid gradient echo sequence (TR, 1900 $\mathrm{ms}$; TE, $4.38 \mathrm{~ms}$; inversion time, $1100 \mathrm{~ms}$; flip angle, $7^{\circ}$; resolution, $1 \times$ $\left.1 \times 1 \mathrm{~mm}^{3}\right)$. T2-weighted images (70 transverse slices) were acquired with turbo spin-echo sequences (TR, $7380 \mathrm{~ms}$; TE, $119 \mathrm{~ms}$; flip angle, $150^{\circ}$; resolution, $1.25 \times 1.25 \times 1.95 \mathrm{~mm}^{3}$ ). Data were collected longitudinally at three age groups: neonates, 1 -year-olds, and 2-year-olds. The variation of age at MRI for each scan is relatively small and the population can be divided into age groups concentrated around 0,1 , and 2 years of age (Li et al., 2013a).

Image preprocessing. All MR images were preprocessed using a standard procedure as detailed in Dai et al. (2013) and Li et al. (2013b). Briefly, it includes (1) skull stripping by a learning-based method (Shi et al., 2012), followed by manual review to ensure the clean skull and dura removal; (2) removing both cerebellum and brain stem by registration of an atlas to the subject using the in-house-developed registration toolkits (Shen and Davatzikos, 2002; Wu et al., 2006; Xue et al., 2006); (3) cor- rection of intensity inhomogeneity using N3 method (Sled et al., 1998); (4) rigid alignment of each image to the age-specific infant brain atlas (Shi et al., 2011) built by the groupwise image registration (Jia et al., 2010); (5) tissue segmentation of infant brain MR images into white matter (WM), gray matter (GM), and CSF by using a dedicated longitudinally guided level-set-based segmentation method (Wang et al., 2013 ,2014), along with longitudinal infant image registration (Shi et al., 2010); and (6) masking and filling noncortical structures, and separation of each brain into left and right hemispheres.

Cortical surface reconstruction and registration. Based on tissue segmentation results, cortical surfaces of each hemisphere for each image were reconstructed by using a deformable surface method (Li et al., 2012, 2013c). Specifically, the inner cortical surface (the WM and GM interface) was first reconstructed by correcting the topological defects in the WM and tessellating the corrected WM as a triangular mesh to ensure a spherical topology for each hemisphere. Because of the strong partial volume effects on MR images of the infant's small brain, the tight sulci in the tissue segmentation results might not be fully visible, leading to incorrect reconstruction of the outer cortical surface. Therefore, we recovered the buried sulci to generate a CSF separation between opposite tight sulci after the tissue segmentation (Li et al., 2012). The inner cortical surface was then deformed toward the reconstruction of the outer cortical surface by preserving its initial topology (Li et al., 2012, 2013c). The inner cortical surface, which had vertex-to-vertex correspondences with the outer cortical surface, was further smoothed, inflated, and mapped to a standard sphere by minimizing the metric distortion between the cortical surface and its spherical representation (Fischl et al., 1999).

For longitudinal cortical development studies, we have to establish both longitudinal (intrasubject) and cross-sectional (intersubject) vertex-to-vertex correspondences of the cortical surfaces. To establish longitudinal vertex-to-vertex cortical correspondences, the inner cortical surface at the $i$-th $(i \in 0,1)$ year of age for each hemisphere of each subject was registered to the corresponding cortical surface at the $i+1$-th year of age by using Spherical Demons, an algorithm that registers spherical images (Yeo et al., 2010). Spherical Demons aligns the cortical folding patterns mapped in the spherical space based on several geometric features of the cortical surface, including mean curvature of the inflated cortical surface, average convexity of the cortical surface, and mean curvature of the cortical surface (Yeo et al., 2010). The deformation map from 0 to 2 years of age of each hemisphere of each subject was then computed by concatenating the deformation map from 0 to 1 year of age and that from 1 to 2 years of age (Li et al., 2013b). To establish crosssectional vertex-to-vertex correspondences of cortical surfaces among different subjects, the surface-based atlas of cortical structures at 2 years of age of each hemisphere was constructed by groupwise registration of cortical surfaces of all subjects at this age by using Spherical Demons. The outer cortical surface of each hemisphere of each subject at 2 years of age was resampled to a standard-mesh tessellation with 163,842 vertices based on deformation from the surface-based atlas at 2 years of age to the individual cortical surface, thus establishing the vertex-to-vertex correspondences across all subjects at 2 years of age for each hemisphere. Based on the longitudinal surface registration results of each subject, the standard-mesh tessellation of each subject at 2 years of age was then warped to 1 year of age and 0 year of age, respectively, thereby establishing the longitudinal vertex-to-vertex correspondences within each subject. In this way, all outer cortical surfaces in the same hemisphere of all subjects were resampled to the same standard-mesh tessellation with 163,842 vertices, thus establishing both longitudinal and cross-sectional cortical vertex-to-vertex correspondences.

Compute global and local cortical GIs. To compute the global and local cortical GIs for each hemisphere of each image, we first generated the cerebral hull volume, which was defined by a boundary running along the margins of gyri without dipping into sulci (Van Essen, 2005). Specifically, we generated the cerebral hull volume by carving the outer cortical surface as a closed volume followed by six iterations of morphological dilation and six iterations of morphological erosion, and then tessellated the cerebral hull volume as a relatively regular triangular mesh (Van Essen, 2005; Li et al., 2013a). In our study, for each hemisphere, the numbers of vertices of the cerebral hull surfaces were 27,424 \pm 2108 , 


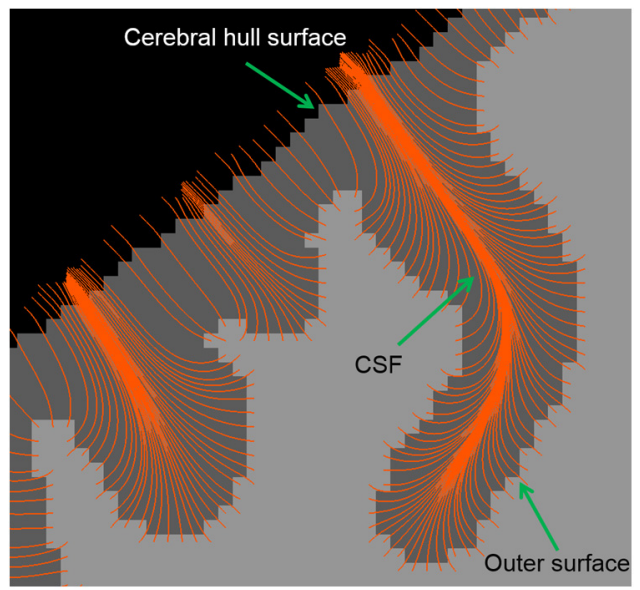

Figure 1. A 2D illustration of establishing correspondences between the outer cortical surface and the cerebral hull surface based on Laplace's equation, with the orange curves indicating the streamlines.

$46,120 \pm 3346$, and $51,647 \pm 3890$ for 0,1 , and 2 years of age, respectively. The average edge lengths of triangles were $0.956 \pm 0.218 \mathrm{~mm}$, $0.960 \pm 0.217 \mathrm{~mm}$, and $0.961 \pm 0.217 \mathrm{~mm}$ for 0,1 , and 2 years of age, respectively. For each vertex on the resampled outer cortical surface with 163,842 vertices, we then determined its corresponding point on the cerebral hull surface by solving the Laplace's equation (Jones et al., 2000; Li et al., 2012). The Laplace's equation is a second-order partial differential equation for a scalar field $\phi$ enclosed between two nonintersecting interfaces:

$$
\Delta \phi=\frac{\partial^{2} \phi}{\partial x^{2}}+\frac{\partial^{2} \phi}{\partial y^{2}}+\frac{\partial^{2} \phi}{\partial z^{2}}=0
$$

By setting the voxels on the carved outer cortical surface as the minimal value and the boundary of the cerebral hull as the maximum value, the Laplace's equation was solved to obtain a harmonic function (Jones et al., 2000; Li et al., 2012). The gradient vector field of the harmonic function was then computed. For each vertex on the resampled outer cortical surface, its streamline ending at the cerebral hull surface was computed accordingly. One elegant advantage of the Laplace's equation is that it establishes a one-to-one point correspondence between the resampled outer cortical surface and the cerebral hull surface. Meanwhile, the streamlines derived from the harmonic function are constrained in sulcal CSF and never intersect each other (Jones et al., 2000; Li et al., 2012). Figure 1 shows a 2D illustration of establishing correspondences between the outer cortical surface and the cerebral hull surface based on the Laplace's equation, with the orange curves indicating the streamlines. Of note, existing methods normally determine the correspondences between the outer cortical surface and the cerebral hull surface based on the Euclidean distance (Schaer et al., 2008) or the geodesic distance constrained in sulcal CSF (Su et al., 2013). Therefore, in the highly convoluted sulci, Euclidean paths and geodesic paths of vertex correspondences might intersect each other and, meanwhile, Euclidean paths might also go through non-CSF regions, leading to biologically less meaningful correspondences between the outer cortical surface and the cerebral hull surface. In contrast, our method based on the Laplace's equation naturally overcomes these limitations.

For each hemisphere of each image, its cortical GI was defined as the ratio between the surface area of its outer cortical surface and that of its cerebral hull surface. For each vertex $x$ on the resampled outer cortical surface, its cortical local GI (LGI) was defined as the ratio between the surface area of its $\mathrm{N}$-ring neighborhood vertices on the outer cortical surface (denoted as $S_{N(x)}^{\text {outer }}$ ) and the surface area of the correspondence vertices on the cerebral hull surface of these $N$-ring neighborhood vertices (denoted as $S_{N^{\prime}(x)}^{\text {hull }}$ ). This is expressed mathematically as follows:

$$
L G I(x)=\frac{S_{N(x)}^{\text {outer }}}{S_{N^{\prime}(x)}^{\text {hull }}}
$$

Note that the $N$-ring neighborhood should be sufficiently large to encompass several cortical folds, but also small enough to reasonably reflect the localized cortical folding. In our study, we used $N=60$, approximately corresponding to the cortical regions with geodesic radii of $28.7 \pm 3.2 \mathrm{~mm}, 40.2 \pm 5.1 \mathrm{~mm}$, and $43.8 \pm 5.5 \mathrm{~mm}$ on the outer cortical surfaces, for 0,1 , and 2 years of age, respectively. However, our findings remained the same for $N=50$ or $N=70$. For illustration, Figure $2 a$ shows the $N$-ring neighborhood (red regions) of the yellow vertex on the resampled outer cortical surfaces in a representative subject at 0,1 , and 2 years of age. Figure $2 b$ shows the corresponding regions (red regions) on the cerebral hull surfaces of $N$-ring neighborhood on the resampled outer cortical surfaces, established by Laplace's equation. Figure $2 c, d$ shows the spatial distributions of the computed cortical LGI at 0,1 , and 2 years of age on both the original surfaces and their inflated surfaces. The insula cortex has the highest LGI because of its extremely folded and deeply buried structure. The intraparietal sulcus also exhibits a relatively high LGI due to its deep and complex folding. Since all outer cortical surfaces of all subjects at all ages were resampled to the same standard-mesh tessellation, the proposed LGI measurement ensured that both the longitudinal and cross-sectional comparisons of LGIs were performed in the anatomically corresponding cortical regions, thus adapted to the changing of brain size. For the early postnatal brain development studies with dynamic changing of brain size, this attribute of brain size adaptiveness in LGI measurement is highly desired. Of note, this attribute cannot be provided by existing methods, which assume the relatively stable brain size across subjects and also compare often the local surface areas enclosed in a sphere with a fixed radius across subjects and ages (Schaer et al., 2008; Toro et al., 2008). Therefore, in these existing methods, the enclosed regions by the sphere are less likely the anatomically corresponding regions across subjects and ages, especially for the dynamically growing infant brains at different ages, eventually leading to less meaningful comparisons.

Figure 3 shows the average LGI on the left hemispheres of all 73 subjects with different $N$-ring neighborhoods, from $N=50$ to $N=70$, at 0 , 1 , and 2 years of age. The trend of LGIs to increase with age is consistently revealed with different $N$-ring neighborhoods. Consistent with the individual's LGI map in Figure 2, the highest LGI is consistently found in the insula cortex, due to its extremely folded and deeply buried structure. For comparison, in Figure 3, we also provide the average LGI of these infant subjects by the conventional method (Schaer et al., 2008) with the fixed radius $20 \mathrm{~mm}$. Although the increasing trend of LGIs can also be revealed by the conventional method, as will be shown in Results, the regional growth pattern of LGIs by the conventional method is quite different from that by our proposed method. For each hemisphere of each subject, the cortical LGI growth percentage map from the $i$-th year to the $j$-th year of age $(i, j \in 0,1,2, i<j)$ was computed by comparing the LGI at each vertex at the $j$-th year to that of its corresponding vertex at the $i$-th year. The cortical LGI growth percentage maps of all subjects were averaged to generate the final cortical LGI growth percentage map. For statistical analysis of high-growth and low-growth regions of LGIs, the normalized LGI was computed for each vertex in each resampled outer cortical surface as the ratio between the LGI and the average LGI in this outer cortical surface.

Statistical analysis. To test the statistical significance of high-growth or low-growth regions of LGIs, we used the surface-based threshold-free cluster enhancement (TFCE) method in Caret software (Hill et al., 2010b). TFCE method has been previously used for testing the statistical significance of high-expansion or low-expansion cortical surface regions between neonates and adults (Hill et al., 2010b), as well as cortical hemispheric structural asymmetries in infants (Hill et al., 2010a; Li et al., 2013a). For each hemisphere, the following operations were performed separately. First, two cortical surfaces of the same hemisphere at different ages of each subject were paired together. Next, a paired $t$ statistic on the normalized LGI at each surface vertex with no spatial smoothing was calculated. Thirdly, the age group identities of each normalized LGI map 

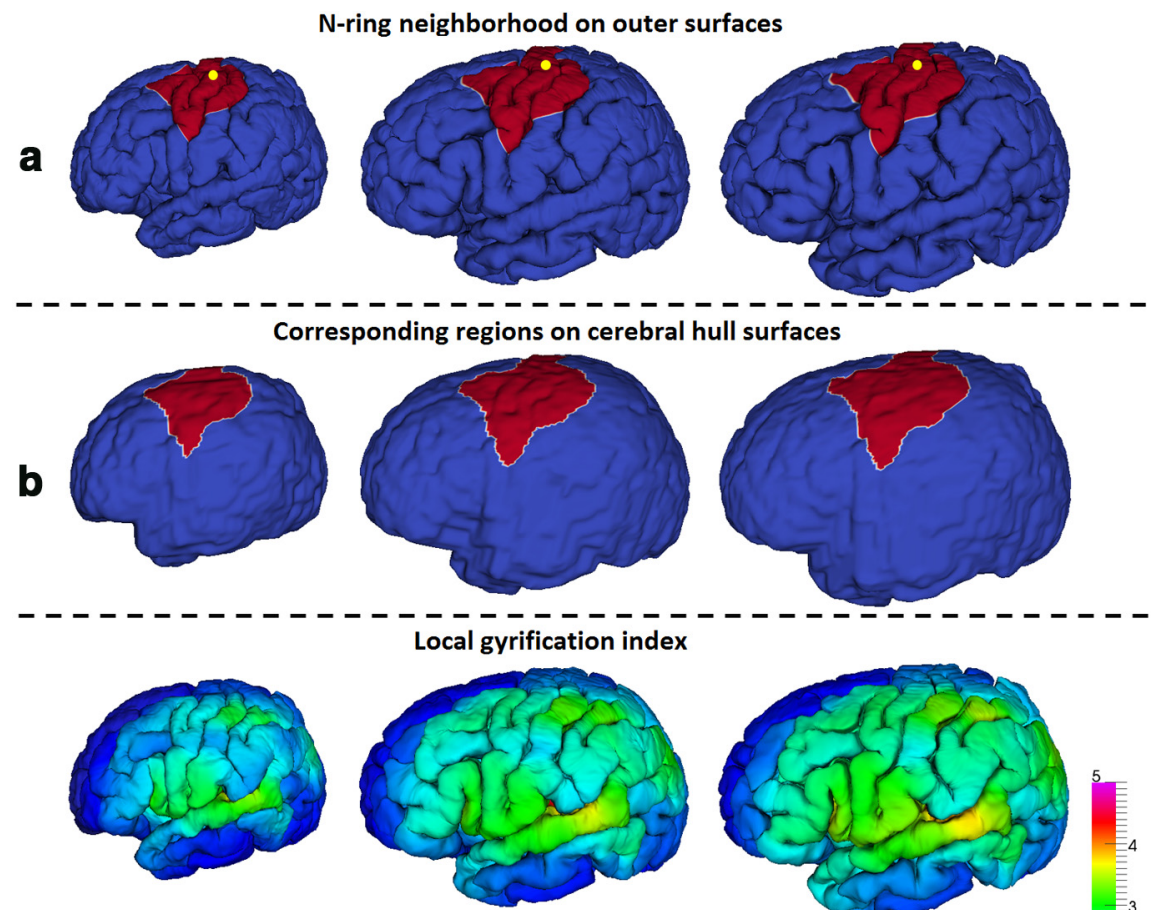

C
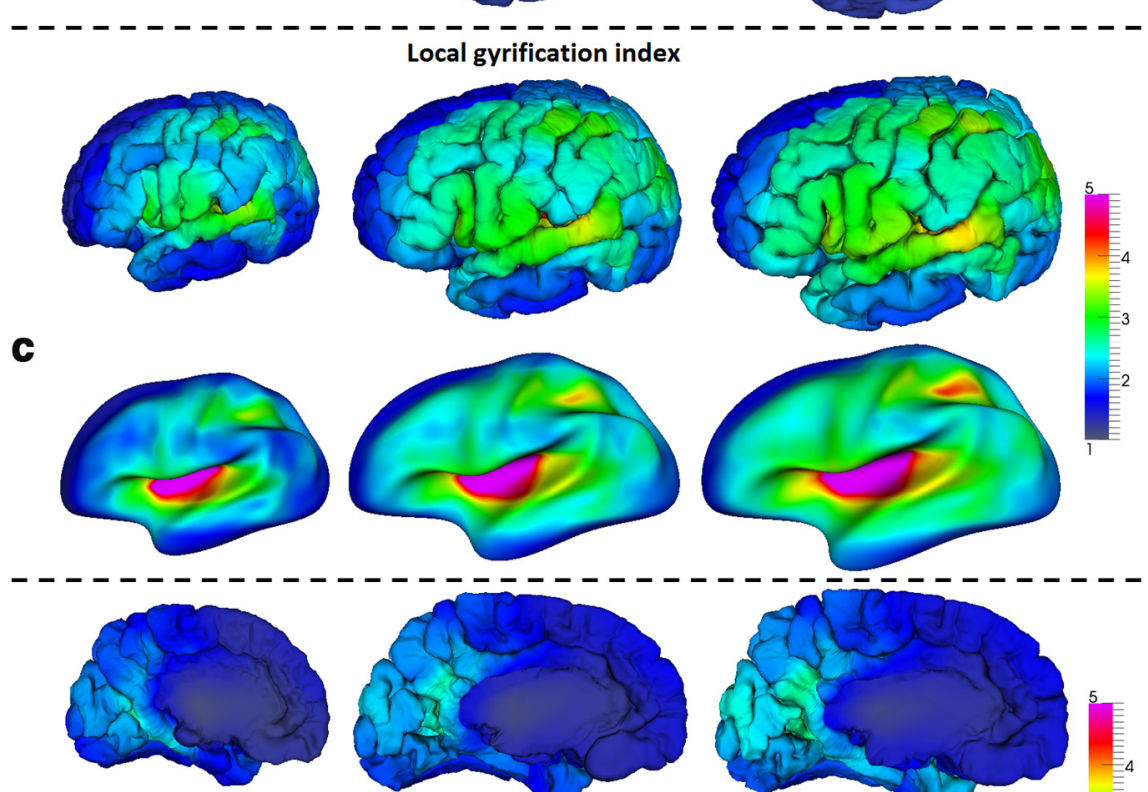

d
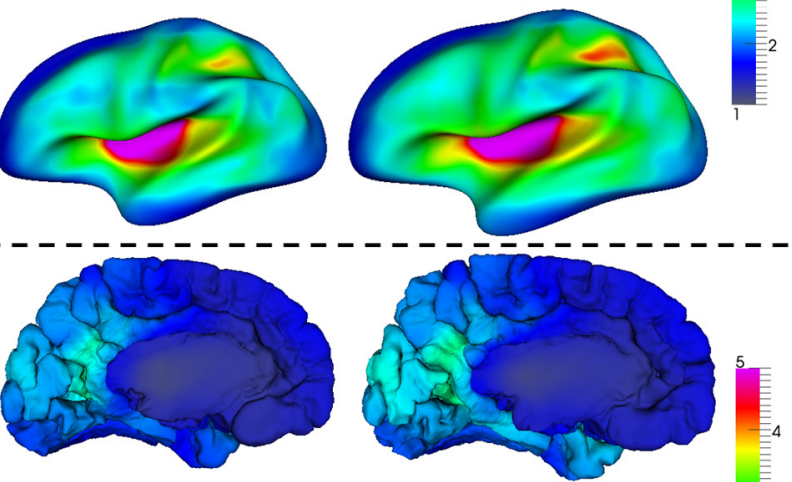

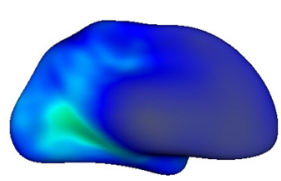

0 year

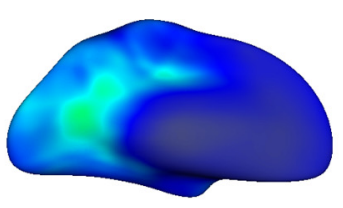

1 year

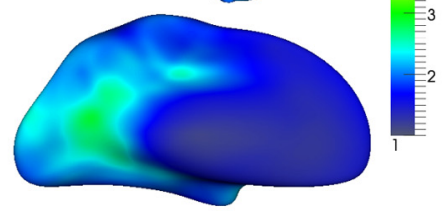

2 years

Figure 2. Illustrations of computing local Gls on a representative subject at 0,1 , and 2 years of age. $\boldsymbol{a}, \mathrm{N}$-ring neighborhood (red) on the resampled outer cortical surfaces of the yellow vertex. $\boldsymbol{b}$, Corresponding regions (red) on the cerebral hull surfaces, established by Laplace's equation. c, Spatial distributions of the local $\mathrm{Gl}$ on the lateral views of both cortical surfaces and their inflated surfaces at 0,1 , and 2 years of age. $\boldsymbol{d}$, Spatial distributions of the local $\mathrm{Gl}$ on the medial views of both cortical surfaces and their inflated surfaces at 0,1 , and 2 years of age. The insula cortex has the highest LGI because of its extremely folded and deeply buried structure.

were randomized 5000 times, and the corresponding paired $t$ maps were generated. Fourthly, each $t$ map was smoothed at 0.5 strength with nine iterations using an average neighbor algorithm (Hill et al., 2010a; Li et al., 2013a). Finally, TFCE, a method originally developed for the volumetric data (Smith and Nichols, 2009), was used to identify the statistically significant clusters (Hill et al., 2010b).

To test the effects of gender and total brain volume (TBV) on the LGI, we adopted SurfStat, a toolbox for statistical analysis of cortical surface data based on random field theory (Chung et al., 2010). Specifically, in each age group, parameter estimates for dependent variable $y_{i}$ (LGI of a vertex or global GI) and the effect of gender were estimated by regression of a general linear model for subject $i$, with the TBV and age as covariates: $y_{i}=\beta_{0}+\beta_{1}$ gender $_{i}+\beta_{2}$ age $e_{i}+\beta_{3}$ TBV $_{i}$ $+\varepsilon_{i}$, where $\varepsilon_{i}$ is an error term. Corrections for multiple comparisons across the cortical surface were performed by random field theory-based cluster analysis (Worsley et al., 2004) using $p<0.05$ (two-tailed) clustersignificance threshold. When testing the effects of the gender and TBV growth on the LGI growth, $y_{i}$ in the equation $y_{i}=\beta_{0}+$ $\beta_{1}$ gender $_{i}+\beta_{2}$ age $_{i}+\beta_{3} T B V_{i}+\varepsilon_{i}$ is substituted by LGI growth rate. Meanwhile, age $e_{i}$ is substituted by the age interval between two scans and $T B V_{i}$ is substituted by the TBV growth rate.

\section{Results}

\section{Cortical GI development in the first 2} years of life

Figure 4 shows the distributions of the longitudinal cortical GIs of the 73 subjects at 0,1 , and 2 years of age. Table 2 provides the mean and SD of the longitudinal cortical GI and average LGI of the 73 subjects. On the left hemisphere, the average cortical GI is 2.01 at birth, 2.32 at 1 year of age, and 2.47 at 2 years of age. On the right hemisphere, the value is 1.98 at birth, 2.31 at 1 year of age, and 2.46 at 2 years of age. The cortical GI is $4.4,1.8$, and $3.1 \%$ larger in males compared with females at 0,1 , and 2 years of age, respectively. However, by including TBV and age as covariates, the difference of GIs between males and females is only significant at 2 years of age $(p<0.05)$ in both left and right hemispheres, but not significant at 0 and 1 year of age. No significant difference of GIs between singletons and twins is found at all three ages, when including the gender, age, and TBV as covariates.

Table 3 provides the mean and SD of the longitudinal cortical GI and average LGI growth percentages of the 73 subjects from 0 to 2 years of age. In the first year, the cortical GI grows substantially, with the average growth percentage of $16.1 \%$ for all subjects. In contrast, the TBV increases extremely dramatically in the first year, with the average growth percentage of $109.7 \%$. In the second year, the cortical GI continues to grow, with the average change percentage of $6.6 \%$ for all subjects, compared with $17.2 \%$ increase of TBV. No significant gender difference of GI growth is found in the first 2 years, when including both age interval and TBV growth as covariates.

\section{Cortical LGI development in the first year}

Figure $5 a$ shows the vertex-wise map of longitudinal cortical LGI growth percentage on both hemispheres in the first year of life. Each region of the cortical surface increases robustly in absolute LGIs. However, the LGI growth rate is highly heterogeneous across the cortex. On the lateral surface, highgrowth regions of LGIs are located in bilateral dorsolateral 


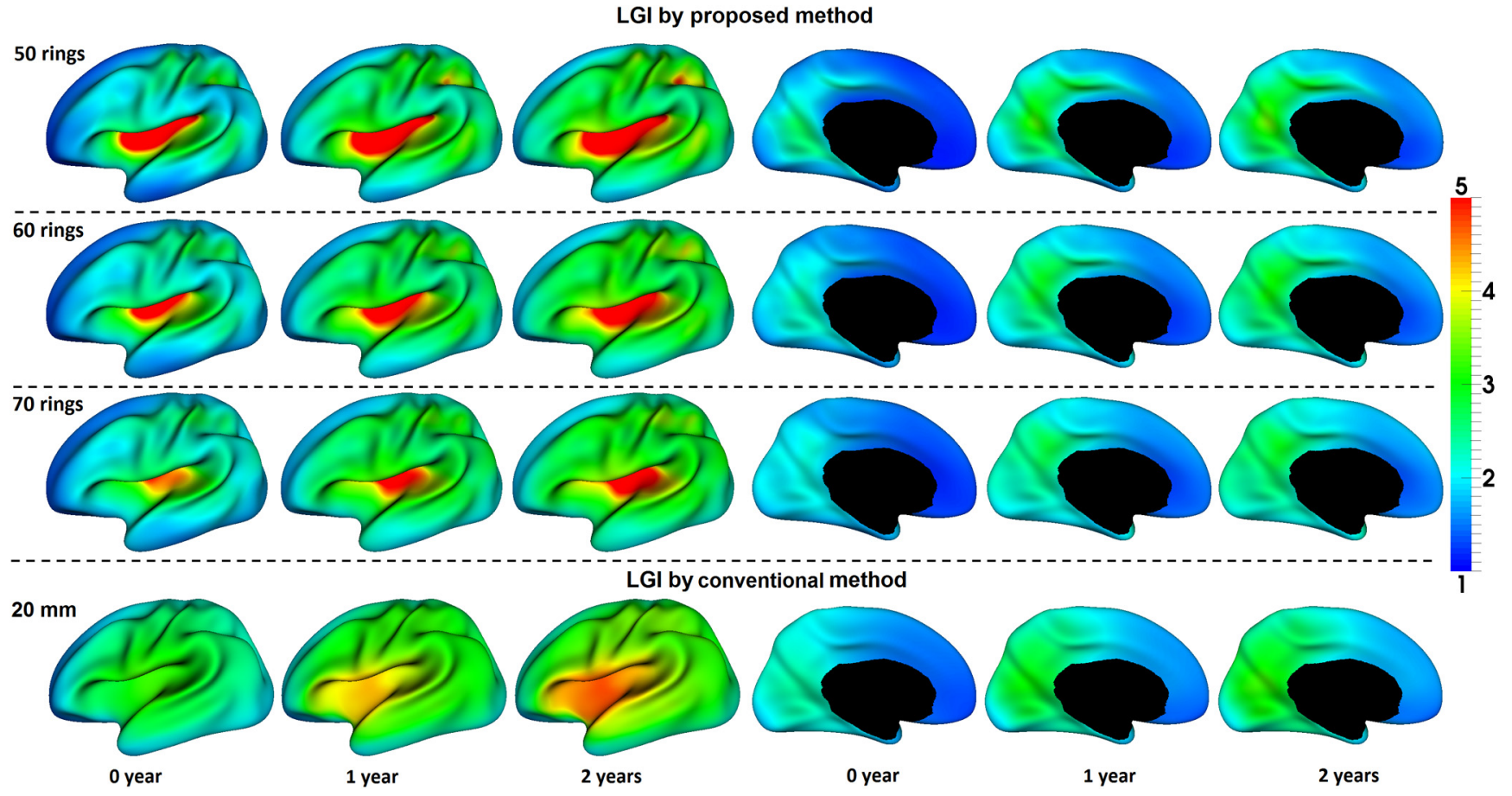

Figure 3. Average local Gl on the left hemispheres of all 73 subjects by the proposed method with different $N$-ring neighborhoods (from $N=50$ to $N=70$ ) and by the conventional method with the radius $20 \mathrm{~mm}$ at 0,1 , and 2 years of age. The highest LGI is consistently found in the insula cortex due to its extremely folded and deeply buried structure.
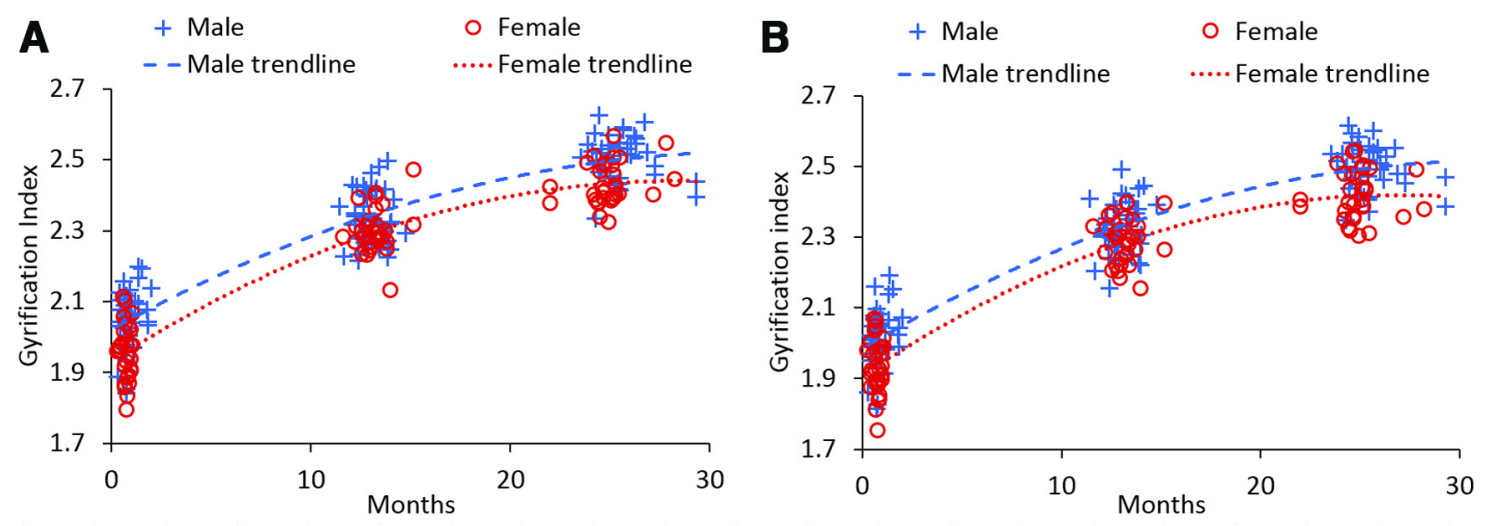

Figure 4. The distribution of longitudinal cortical $\mathrm{Gls}$ of 73 subjects at 0,1 , and 2 years of age. $\boldsymbol{A}$, Left hemisphere; $\boldsymbol{B}$, right hemisphere.

Table 2. The mean and SD of longitudinal cortical GI and average LGI of the 73 subjects at 0,1 , and 2 years of age, respectively

\begin{tabular}{|c|c|c|c|c|c|c|}
\hline \multirow[b]{2}{*}{ Gl } & \multicolumn{2}{|l|}{ 0-year-old } & \multicolumn{2}{|l|}{ 1-year-old } & \multicolumn{2}{|l|}{ 2-year-old } \\
\hline & Left & Right & Left & Right & Left & Right \\
\hline \multicolumn{7}{|l|}{ Subjects } \\
\hline All $(n=73)$ & $2.01 \pm 0.09$ & $1.98 \pm 0.09$ & $2.32 \pm 0.07$ & $2.31 \pm 0.07$ & $2.47 \pm 0.07$ & $2.46 \pm 0.08$ \\
\hline Female $(n=31)$ & $1.96 \pm 0.08$ & $1.94 \pm 0.08$ & $2.30 \pm 0.06$ & $2.29 \pm 0.07$ & $2.43 \pm 0.06$ & $2.42 \pm 0.07$ \\
\hline \multicolumn{7}{|l|}{ Average LGI } \\
\hline All $(n=73)$ & $2.01 \pm 0.10$ & $1.95 \pm 0.10$ & $2.39 \pm 0.08$ & $2.33 \pm 0.08$ & $2.57 \pm 0.08$ & $2.51 \pm 0.09$ \\
\hline
\end{tabular}

prefrontal cortices; in bilateral inferior and middle temporal cortices; in bilateral posterior parietal cortices; in bilateral inferior parietal cortices; and in Broca's area. Low-growth regions of LGIs are located in bilateral postcentral and precentral gyri and in bilateral posterior perisylvian cortices, including the auditory cortex. On the medial surface, high- growth regions of LGIs are found in bilateral precuneus and posterior cingulate cortices. Low-growth regions of LGIs are found in bilateral medial occipital cortices; in medial temporal cortices; in medial superior, and orbital frontal cortices; and in bilateral anterior cingulate cortices. The right column of Figure $5 a$ shows the statistically significant clusters of high- 
Table 3. The mean and SD of longitudinal cortical GI and average LGI growth percentages of the 73 subjects from 0 to 2 years of age

\begin{tabular}{|c|c|c|c|c|c|c|}
\hline \multirow[b]{2}{*}{ Gl } & \multicolumn{2}{|c|}{$0-1$ year growth (\%) } & \multicolumn{2}{|c|}{$1-2$ year growth (\%) } & \multicolumn{2}{|c|}{$0-2$ year growth (\%) } \\
\hline & Left & Right & Left & Right & Left & Right \\
\hline \multicolumn{7}{|l|}{ Subjects } \\
\hline All $(n=73)$ & $15.6 \pm 5.0$ & $16.6 \pm 4.5$ & $6.5 \pm 2.1$ & $6.7 \pm 2.1$ & $23.1 \pm 4.9$ & $24.4 \pm 4.5$ \\
\hline Male $(n=42)$ & $14.6 \pm 5.1$ & $15.8 \pm 4.8$ & $6.7 \pm 2.4$ & $7.1 \pm 2.3$ & $22.2 \pm 5.2$ & $24.0 \pm 4.9$ \\
\hline Female $(n=31)$ & $17.0 \pm 4.6$ & $17.7 \pm 3.9$ & $6.2 \pm 1.7$ & $6.1 \pm 1.6$ & $24.2 \pm 4.4$ & $24.9 \pm 4.0$ \\
\hline \multicolumn{7}{|l|}{ Average LGI } \\
\hline All $(n=73)$ & $19.1 \pm 5.1$ & $19.4 \pm 5.0$ & $7.6 \pm 2.5$ & $7.7 \pm 2.4$ & $28.0 \pm 5.4$ & $28.6 \pm 4.9$ \\
\hline Male $(n=42)$ & $17.8 \pm 5.4$ & $18.4 \pm 5.1$ & $7.9 \pm 2.7$ & $8.2 \pm 2.6$ & $27.0 \pm 5.7$ & $28.0 \pm 5.0$ \\
\hline Female $(n=31)$ & $20.7 \pm 5.1$ & $20.8 \pm 4.7$ & $7.2 \pm 2.1$ & $7.0 \pm 1.8$ & $29.3 \pm 4.6$ & $29.3 \pm 4.5$ \\
\hline
\end{tabular}

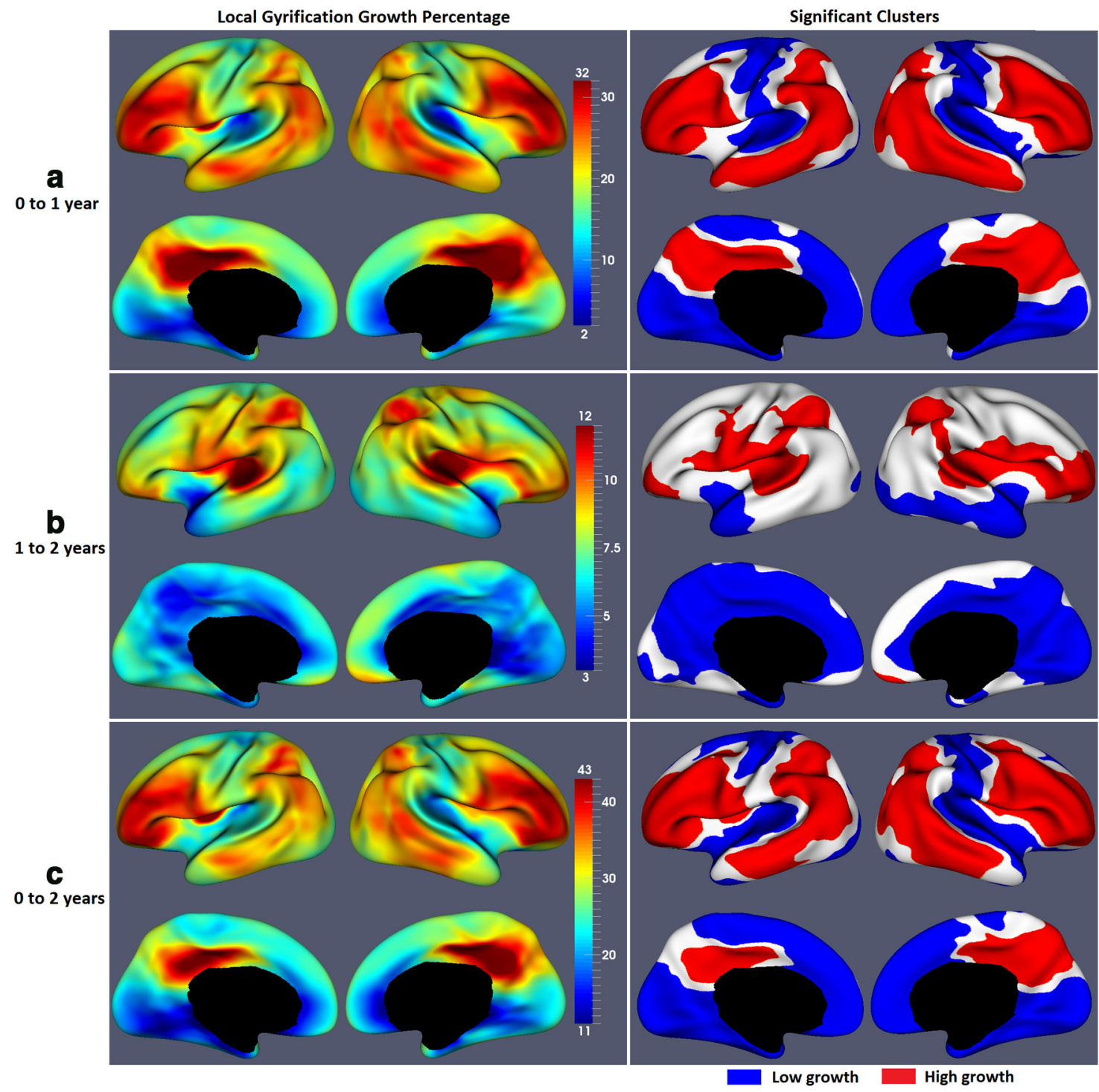

Figure 5. Longitudinal cortical LGI development in the first 2 years of life for 73 subjects by the proposed method with $N=60$. The left column shows the average growth percentage of the cortical LGI. The right column shows the significant high-growth and low-growth regions of LGIs by TFCE method $(p<0.01)$. Blue clusters are the low-growth regions of $L G l s$. Red clusters are the high-growth regions of $L G \mid s$. $a-c$, Results for $0-1$ year, $1-2$ years, and $0-2$ years.

growth and low-growth regions of LGIs by the TFCE method $(p<0.01)$. Blue clusters show lower-than average growth regions of LGIs. Red clusters show higher-than-average growth regions of LGIs.

To demonstrate that our findings are not sensitive to the ring number $N$ in computing LGIs, we also generated the statistical results of high-growth and low-growth regions of LGIs with $N=$ 50 and $N=70$, as shown in Figure 6 . As can be seen, the spatial distributions of high-growth and low-growth regions are quite similar to the findings with $N=60$. For comparison, we also computed the LGI growth rate and its statistically significant regions by using the conventional method (Schaer et al., 2008) with the fixed radius of $20 \mathrm{~mm}$, as shown in Figure $7 a$. We can see that the LGI growth pattern by the conventional method is quite different from that by our proposed method. For example, the proposed method reveals the low growth of LGIs in unimodal cortex 


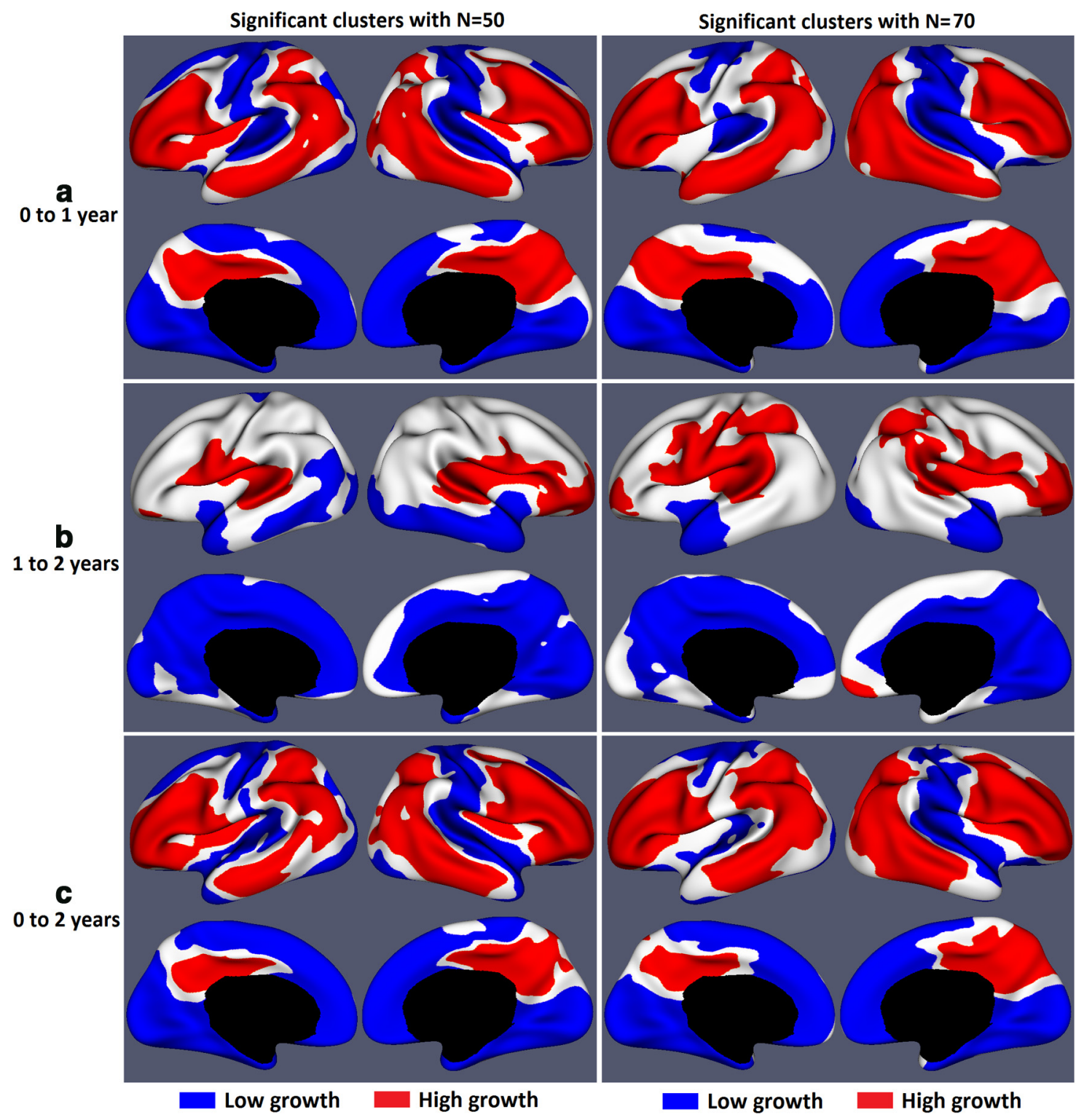

Figure 6. Significant clusters of high-growth (red) and low-growth (blue) regions of $L$ Gls in the first 2 years of life found from 73 subjects by TFCE $\operatorname{method}(p<0.01)$ with $N=50$ and $N=70$. $\boldsymbol{a}-\boldsymbol{c}$, Results for $0-1$ year $(\boldsymbol{a}), 1-2$ years $(\boldsymbol{b})$, and $0-2$ years $(\boldsymbol{c})$.

and the high growth in association cortex. In contrast, the conventional method cannot find such clearly distinguished pattern between the unimodal cortex and association cortex. The main reason is that, for the dynamically growing infant brains, the conventional method with the fixed radius actually compares LGIs in the anatomically different cortical regions (of different ages), thus leading to less meaningful results for the LGI growth patterns.

Cortical LGI development in the second year

Figure $5 b$ shows the vertex-wise map of longitudinal cortical LGI growth percentage on both hemispheres in the second year. The LGI of each vertex of the cortical surface continues to increase, although the growth rate is considerably smaller than that in the first year. Similar to the finding in the first year, the LGI also exhibits strong regional heterogeneity in the growth rate. However, both high-growth and low-growth regions of LGIs in the second year are largely different from those in the first year. Specifically, the high-growth regions of LGIs are mainly located in bilateral perisylvian cortices, in bilateral superior parietal cortices, and in bilateral frontal poles. The low-growth regions are mainly found in bilateral temporal poles; in the right inferior temporal cortex; in bilateral medial occipital, cingulate, and precuneus cortices; and in left medial superior frontal and paracentral cortices. Statistically significant clusters of high-growth and low-growth regions of LGIs by the TFCE method $(p<0.01)$ are provided in the right column of Figure $5 b$. Similarly, as shown in Figure $7 b$, the LGI growth pattern in the second year by the conventional method is also different from that by our proposed method, again demonstrating the advantage of our proposed method.

\section{Overall cortical LGI development in the first 2 years}

Figure $5 c$ shows the vertex-wise map of longitudinal cortical LGI growth percentage on both hemispheres in the first 2 years. As the cortical LGI growth in the first year is considerably larger than that in the second year, the cortical LGI growth in the first 2 years is mainly dominated by its growth in the first year. As a result, the 


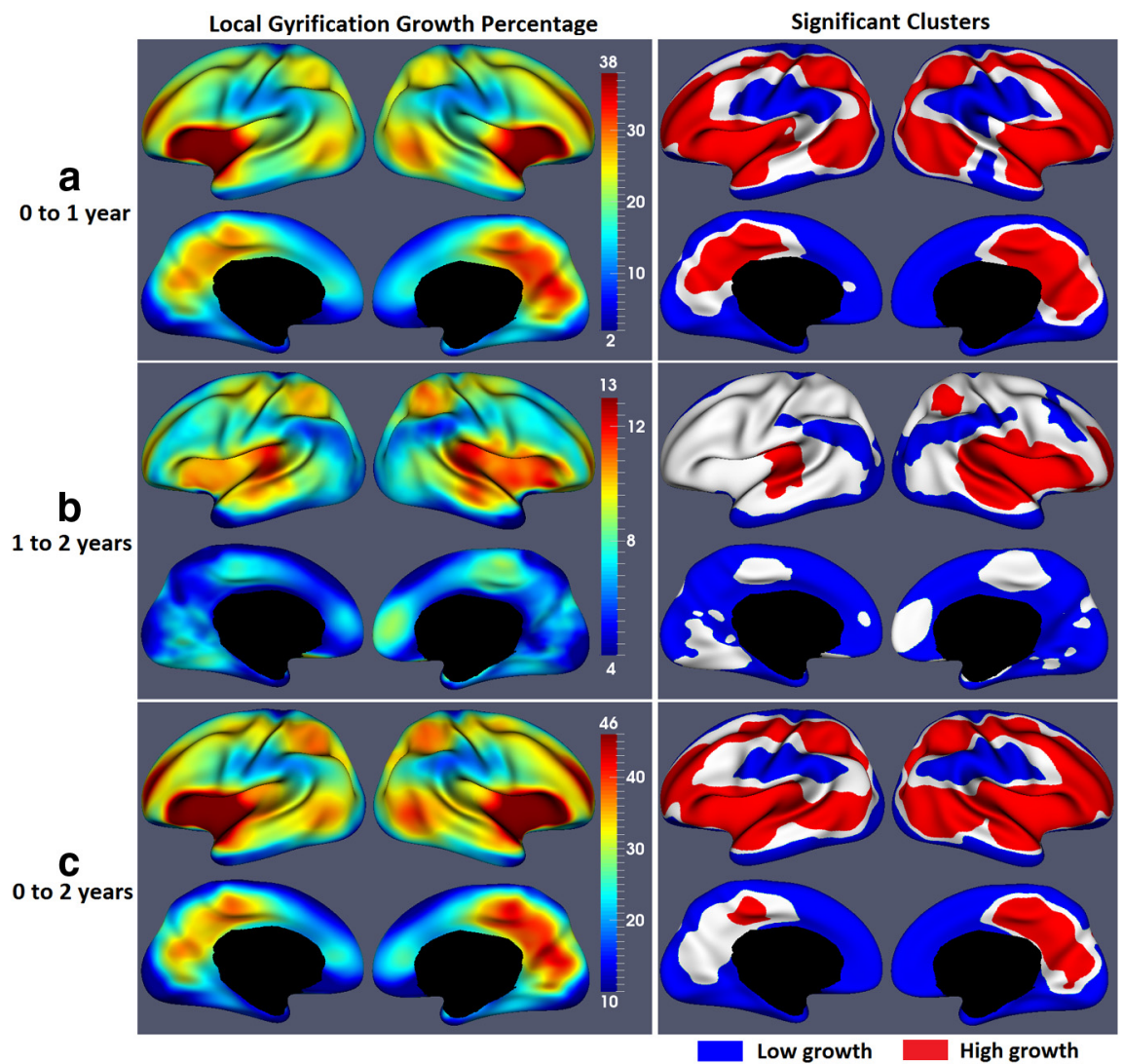

Figure 7. Longitudinal cortical LGI development in the first 2 years of life for 73 subjects, computed by the conventional method with the radius $20 \mathrm{~mm}$. The left column shows the average growth percentage of the cortical LGls. The right column shows the significant high-growth and low-growth regions of LGIs by TFCE method ( $p<0.01)$. Blue and red clusters are the low-growth and high-growth regions of $L G l s$, respectively. $\boldsymbol{a}-\boldsymbol{c}$, Results for $0-1$ year $(\boldsymbol{a}), 1-2$ years $(\boldsymbol{b})$, and $0-2$ years $(\boldsymbol{c})$.

\section{Gender Differences on LGI}

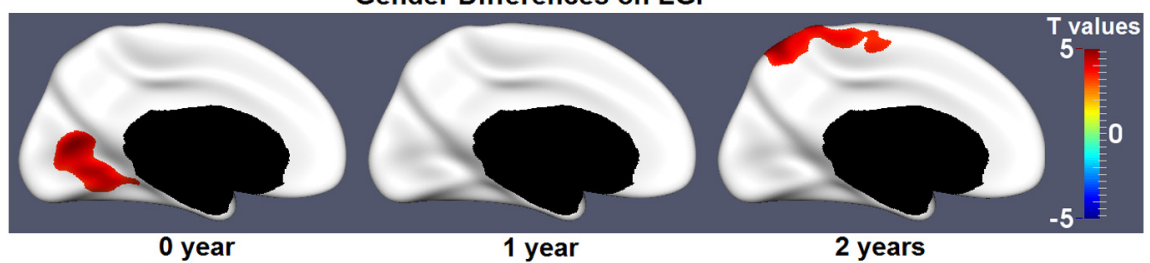

Figure 8. Significant clusters of gender differences on LGIs ( $p<0.05$, multiple-comparisons corrected), at 0,1 , and 2 years of age, by including TBV as a confounding factor. Red clusters indicate that males have larger LGIs than females. No significant cluster of gender difference on LGls is found in other cortical regions.

high-growth and low-growth regions of LGIs in the first 2 years are highly similar to those identified in the first year. Specifically, high-growth regions are found in dorsolateral prefrontal, inferior and middle temporal, superior and inferior parietal cortices; in Broca's area; and in precuneus and posterior cingulate cortices. Low-growth regions are located in postcentral and precentral gyri; in posterior perisylvian cortices; in medial occipital, medial temporal, medial superior, and orbital frontal cortices; and in the anterior cingulate gyrus.

\section{Gender effects on LGI growth}

Figure 8 shows the significant clusters $(p<0.05$, multiplecomparisons corrected) of gender differences on LGIs, at 0,1 , and 2 years of age, by including TBV as a confounding factor. At 0 year of age, the cortical region around the left calcarine sulcus in males exhibits significantly larger LGIs than that in females, and no significant gender difference is found in other cortical regions in both left and right hemispheres. At 1 year of age, no significant cluster of gender difference of LGIs is found in two hemispheres. At 2 years of age, the left paracentral cortex and precuneus cortex in males exhibit significantly larger LGIs than those in females, and no significant gender difference is found in other cortical regions. Meanwhile, we also investigated the gender effects on the growth rate of LGIs in both first and second years of age, and found no significant gender difference in any cortical regions when including TBV growth as a confounding factor.

\section{Brain volume growth effects on LGI growth}

Figure 9 shows the significant clusters $(p<0.05$, multiple-comparisons corrected) of positive correlations between LGI growth and the TBV growth, colorcoded by $t$ values. In the first year, most of cortical regions are significant, except the bilateral insula cortices, bilateral Heschl's gyri, and bilateral medial temporal and occipital cortices. The strength of this correlation varies regionally and is particularly significant in the prefrontal cortex. In the second year, significant regions are concentrated on the lateral surface, including bilateral prefrontal cortices, bilateral precentral gyri, and bilateral parietal and temporal cortices. The strength of this correlation is particularly significant in the right temporal cortex. In both first and second years of age, TBV growth is statistically larger than LGI growth in every region.

\section{Discussion}

The cortical GI has age-related and marked development, with $16.1 \%$ increase in the first year and $6.6 \%$ increase in the second year. By 2 years of age, the cortical GI increases $23.7 \%$ to reach 2.47 , compared with the value of 1.99 at birth. Longitudinal imaging studies found the decrease of cortical GIs from 2.53 at 6 years of age, with the annual decrease of $<0.5 \%$ (Raznahan et al., 2011). Although it is unclear for the cortical GI development between 2 and 6 years of age, our results implicate that the GI is likely to peak during this stage, distinct from the trajectories of the brain volume, cortical thickness, and surface area, which all peak in late childhood/early adolescence (Lenroot et al., 2007; Raznahan et al., 2011; Nie et al., 2013a). Longitudinal follow-up of this cohort will help better define the developmental trajectory of the GI and its relationship to other brain attributes.

The cortical LGI development is highly age-related and regionally heterogeneous in the first 2 years. In the first year, the high-growth regions of LGIs are mainly located in heteromodal association cortex, including prefrontal, inferior, and middle temporal cortices, and parietal cortices, while the low-growth 
regions are found in unimodal cortex, including primary motor, somatosensory, auditory, and visual cortices. In the cortical surface area expansion study, the highexpansion regions in the first year are found in the prefrontal, medial orbitofrontal, temporal, superior parietal, and occipital cortices and in the postcentral gyrus, whereas the low-expansion regions are found in the precentral gyrus and in the superior frontal, precuneus, cingulate, and insula cortices (Li et al., 2013b), suggesting distinct developmental patterns between local surface area and local cortical folding. In the second year, the highgrowth regions of LGIs are mainly located in perisylvian regions, including Broca's area, the auditory cortex, and the articulatory motor cortex, as well as frontal pole and superior parietal cortex, while the low-growth regions are found in the temporal poles, the medial surface, and the right inferior temporal cortex. Again, this growth pattern of LGIs is distinct from the surface area expansion, with the high-expansion regions in parietal, inferior temporal, middle, and superior frontal cortices, and also the low-expansion regions in visual, auditory, motor, and insula cortices (Li et al., 2013b). Taken together, in the first 2 years, the cortical LGI has distinct developmental patterns from cortical surface area, and also the heteromodal association cortex exhibits high growth of LGIs, while the unimodal sensory and motor cortex exhibits low growth.

Rapid cortical GI/LGI growth in early postnatal period is likely related to the increase of dendritic arborization and also the growth of the terminal axon arborization, synaptogenesis, and glial proliferation (Huttenlocher, 1990; Rakic et al., 1994; Petanjek et al., 2008, 2011). The mechanisms underlying this agerelated and regionally heterogeneous developmental pattern of LGIs are not sufficiently understood, but it might relate to cellular, functional, and genetic nonuniformities during development. In general, high-growth regions of LGIs tend to be less mature at term birth both structurally and functionally, and also tend to reach maturation more slowly than the low-growth regions. At birth, in the low-growth visual and auditory cortices, synaptic density is $50-100 \%$ greater and is closer to peak density than in the high-growth prefrontal cortex (Huttenlocher and Dabholkar, 1997; Hill et al., 2010b). After birth, synapse densities increase rapidly, peaking at 3 months for the low-growth auditory cortex and 3.5 years for high-growth prefrontal cortex (Huttenlocher and Dabholkar, 1997). In newborns, the local cerebral metabolic rate for glucose is markedly higher in the low-growth sensorimotor, auditory, and visual cortices than in the highgrowth dorsolateral prefrontal cortex (Chugani and Phelps, 1986). The high-growth association cortex also exhibits the most protracted course of GM maturation than the low-growth visual and sensorimotor cortices (Gogtay et al., 2004; Shaw et al., 2008). In infants, the resting-state networks are present in the lowgrowth sensorimotor, visual, and auditory cortices (Fransson et al., 2007, 2011; Lin et al., 2008), whereas the default network involving high-growth inferior parietal, prefrontal, and temporal cortices does not fully develop until 2 years of age (Gao et al., 2009). Evolutionary high expansion of cortical surface area between macaque and human is also found in the association cortex, including prefrontal, temporal, and parietal association areas (Hill et al., 2010b). Functional MRI studies also show that the intersubject variability of functional connectivity is significantly higher in the high-growth association cortex, including lateral prefrontal lobe and temporal-parietal junction, while lower in the sensory and motor cortices (Mueller et al., 2013). The highgrowth association cortex corresponds to phylogenetically latedeveloping regions that are essential to the human-specific cognitive functions, such as reasoning and language (GoldmanRakic, 1988; Mueller et al., 2013). All the primary and secondary cortical folding are established at term birth (Chi et al., 1977). Thus, our results might suggest that the heteromodal association cortex has less matured folding than the unimodal sensory and motor cortex at birth. As a result, the LGI of the heteromodal association cortex, which is probably less genetically influenced during development (Brun et al., 2009), develops more rapidly after birth under the more variable impact of postnatal environmental factors, likely eventually leading to more variable functional connectivity across individuals in these regions (Mueller et al., 2013).

When covarying out TBV, males exhibit significantly larger GIs than females at 2 years of age, and also larger LGIs than females in one region at birth and another region at 2 years of age. These results may suggest that the gender differences in cortical folding exist at birth and continue to evolve during the postnatal development. In the first 2 years, the LGI growth in most cortical regions is positively correlated with the TBV growth, suggesting that the LGI growth is largely induced by the TBV growth. The correlation between the LGI growth and TBV growth in the first year is particularly significant in the prefrontal cortex, which is involved in various high-level cognitive functions (Wood and Grafman, 2003; Petrides, 2005). In adults, the correlation between brain size and the folding degree of the prefrontal cortex is found to be particularly significant (Toro et al., 2008). The expansion of the prefrontal cortex is regarded as a major evolutionary landmark of human cognition (Toro et al., 2008). However, the underlying mechanism of the relationship between LGI growth and TBV growth is still unclear, although the cortical folding development is thought to be related to the corticocortical connectivity (Van Essen, 1997) or differential expansion of superior and inferior cortical layers (Caviness, 1975).

Abnormal cortical gyrification is found in many neurodevelopmental disorders, such as schizophrenia (Palaniyappan and Liddle, 2012; Schultz et al., 2013), autism (Jou et al., 2010; Wallace et al., 2013), and Williams syndrome (Gaser et al., 2006). Increasing evidence suggests that many neurodevelopmental dis- 
orders are likely the result of abnormal brain development in early postnatal stages. Since GI growth in the first 2 years is much larger than that of any other postnatal stages, the gyrification abnormalities are more likely to emerge during this stage. Therefore, studying cortical GI/LGI developments in infants at high risk for neurodevelopmental disorders would provide valuable information for understanding these disorders.

Our method used the $\mathrm{N}$-rings neighborhood in the cortical surface for computing LGIs. As the highly folded regions could have denser triangles than the regions with less complexity, we used a relatively large $N=60$, in contrast to the small $N$-rings neighborhood as used by Lebed et al. (2013), to alleviate the effects of possible nonuniform meshes and still capture local folding. Regions with $N=60$ correspond to the cortical regions with geodesic radii of $28.7 \pm 3.2 \mathrm{~mm}, 40.2 \pm 5.1 \mathrm{~mm}$, and $43.8 \pm 5.5$ $\mathrm{mm}$ on cortical surfaces, for 0,1 , and 2 years of age, respectively. It is worth noting that a small variance of radius of $N$-ring neighborhood did not change the overall patterns of high-growth and low-growth regions of LGIs. A potential limitation of the current study is that the GI is genetically affected (Rogers et al., 2010) and thus there might exist other more appropriate statistical methods to consider genetic information in our twin subjects, which will be definitely our future work.

In summary, we developed an infant-specific method for mapping longitudinal cortical local gyrification development. Via 219 longitudinal 3T MRI scans from 73 healthy subjects, we systemically characterized the longitudinal cortical GI and LGI development in the first 2 years of life. To our knowledge, this is the first study of longitudinal developmental trajectories and gender differences of cortical GIs and LGIs in early postnatal stages. We found that the cortical GI had age-related, marked development in the first 2 years. We also found the regionally heterogeneous cortical LGI development during this stage, with the high-growth regions located in association cortex, whereas the low-growth regions located in sensorimotor, auditory, and visual cortices. Given the regionally heterogeneous growth pattern of the cortical LGI, it would be interesting to investigate how this relates to the underlying WM connectivity (Yap et al., 2011; Nie et al., 2013b; Zhu et al., 2013) and also to early cognitive and motor development in infants.

\section{References}

Armstrong E, Schleicher A, Omran H, Curtis M, Zilles K (1995) The ontogeny of human gyrification. Cereb Cortex 5:56-63. CrossRef Medline

Brun CC, Leporé N, Pennec X, Lee AD, Barysheva M, Madsen SK, Avedissian C, Chou YY, de Zubicaray GI, McMahon KL, Wright MJ, Toga AW, Thompson PM (2009) Mapping the regional influence of genetics on brain structure variability-a tensor-based morphometry study. Neuroimage 48:37-49. CrossRef Medline

Caviness VS Jr (1975) Mechanical model of brain convolutional development. Science 189:18-21. CrossRef Medline

Chi JG, Dooling EC, Gilles FH (1977) Gyral development of the human brain. Ann Neurol 1:86-93. CrossRef Medline

Chugani HT, Phelps ME (1986) Maturational changes in cerebral function in infants determined by 18 FDG positron emission tomography. Science 231:840-843. CrossRef Medline

Chung MK, Worsley KJ, Nacewicz BM, Dalton KM, Davidson RJ (2010) General multivariate linear modeling of surface shapes using SurfStat. Neuroimage 53:491-505. CrossRef Medline

Dai Y, Shi F, Wang L, Wu G, Shen D (2013) iBEAT: a toolbox for infant brain magnetic resonance image processing. Neuroinformatics 11:211225. CrossRef Medline

Fan Y, Shi F, Smith JK, Lin W, Gilmore JH, Shen D (2011) Brain anatomical networks in early human brain development. Neuroimage 54:1862-1871. CrossRef Medline

Fischl B, Sereno MI, Dale AM (1999) Cortical surface-based analysis. II: inflation, flattening, and a surface-based coordinate system. Neuroimage 9:195-207. CrossRef Medline

Fransson P, Skiöld B, Horsch S, Nordell A, Blennow M, Lagercrantz H, Aden U (2007) Resting-state networks in the infant brain. Proc Natl Acad Sci U S A 104:15531-15536. CrossRef Medline

Fransson P, Aden U, Blennow M, Lagercrantz H (2011) The functional architecture of the infant brain as revealed by resting-state fMRI. Cereb Cortex 21:145-154. CrossRef Medline

Gao W, Zhu H, Giovanello KS, Smith JK, Shen D, Gilmore JH, Lin W (2009) Evidence on the emergence of the brain's default network from 2-weekold to 2-year-old healthy pediatric subjects. Proc Natl Acad Sci U S A 106:6790-6795. CrossRef Medline

Gaser C, Luders E, Thompson PM, Lee AD, Dutton RA, Geaga JA, Hayashi KM, Bellugi U, Galaburda AM, Korenberg JR, Mills DL, Toga AW, Reiss AL (2006) Increased local gyrification mapped in Williams syndrome. Neuroimage 33:46-54. CrossRef Medline

Gilmore JH, Shi F, Woolson SL, Knickmeyer RC, Short SJ, Lin W, Zhu H, Hamer RM, Styner M, Shen D (2012) Longitudinal development of cortical and subcortical gray matter from birth to 2 years. Cereb Cortex 22:2478-2485. CrossRef Medline

Gogtay N, Giedd JN, Lusk L, Hayashi KM, Greenstein D, Vaituzis AC, Nugent TF 3rd, Herman DH, Clasen LS, Toga AW, Rapoport JL, Thompson PM (2004) Dynamic mapping of human cortical development during childhood through early adulthood. Proc Natl Acad Sci U S A 101:8174-8179. CrossRef Medline

Goldman-Rakic PS (1988) Topography of cognition: parallel distributed networks in primate association cortex. Annu Rev Neurosci 11:137-156. CrossRef Medline

Hill J, Dierker D, Neil J, Inder T, Knutsen A, Harwell J, Coalson T, Van Essen D (2010a) A surface-based analysis of hemispheric asymmetries and folding of cerebral cortex in term-born human infants. J Neurosci 30: 2268-2276. CrossRef Medline

Hill J, Inder T, Neil J, Dierker D, Harwell J, Van Essen D (2010b) Similar patterns of cortical expansion during human development and evolution. Proc Natl Acad Sci U S A 107:13135-13140. CrossRef Medline

Huttenlocher PR (1990) Morphometric study of human cerebral cortex development. Neuropsychologia 28:517-527. CrossRef Medline

Huttenlocher PR, Dabholkar AS (1997) Regional differences in synaptogenesis in human cerebral cortex. J Comp Neurol 387:167-178. CrossRef Medline

Jia H, Wu G, Wang Q, Shen D (2010) ABSORB: atlas building by selforganized registration and bundling. Neuroimage 51:1057-1070. CrossRef Medline

Jones SE, Buchbinder BR, Aharon I (2000) Three-dimensional mapping of cortical thickness using Laplace's equation. Hum Brain Mapp 11:12-32. CrossRef Medline

Jou RJ, Minshew NJ, Keshavan MS, Hardan AY (2010) Cortical gyrification in autistic and Asperger disorders: a preliminary magnetic resonance imaging study. J Child Neurol 25:1462-1467. CrossRef Medline

Knickmeyer RC, Gouttard S, Kang C, Evans D, Wilber K, Smith JK, Hamer RM, Lin W, Gerig G, Gilmore JH (2008) A structural MRI study of human brain development from birth to 2 years. J Neurosci 28:1217612182. CrossRef Medline

Lebed E, Jacova C, Wang L, Beg MF (2013) Novel surface-smoothing based local gyrification index. IEEE Trans Med Imaging 32:660-669. CrossRef Medline

Lenroot RK, Gogtay N, Greenstein DK, Wells EM, Wallace GL, Clasen LS, Blumenthal JD, Lerch J, Zijdenbos AP, Evans AC, Thompson PM, Giedd JN (2007) Sexual dimorphism of brain developmental trajectories during childhood and adolescence. Neuroimage 36:1065-1073. CrossRef Medline

Li G, Nie J, Wu G, Wang Y, Shen D, Shen D (2012) Consistent reconstruction of cortical surfaces from longitudinal brain MR images. Neuroimage 59:3805-3820. CrossRef Medline

Li G, Nie J, Wang L, Shi F, Lyall AE, Lin W, Gilmore JH, Shen D (2013a) Mapping longitudinal hemispheric structural asymmetries of the human cerebral cortex from birth to 2 years of age. Cereb Cortex. Advance online publication. Retrieved February 19, 2014. doi:10.1093/cercor/bhs413. CrossRef Medline

Li G, Nie J, Wang L, Shi F, Lin W, Gilmore JH, Shen D (2013b) Mapping region-specific longitudinal cortical surface expansion from birth to 2 years of age. Cereb Cortex 23:2724-2733. CrossRef Medline 
Li G, Nie J, Wang L, Shi F, Gilmore JH, Lin W, Shen D (2013c) Measuring the dynamic longitudinal cortex development in infants by reconstruction of temporally consistent cortical surfaces. Neuroimage 90C:266279. CrossRef Medline

Lin W, Zhu Q, Gao W, Chen Y, Toh CH, Styner M, Gerig G, Smith JK, Biswal B, Gilmore JH (2008) Functional connectivity MR imaging reveals cortical functional connectivity in the developing brain. AJNR Am J Neuroradiol 29:1883-1889. CrossRef Medline

Luders E, Narr KL, Bilder RM, Szeszko PR, Gurbani MN, Hamilton L, Toga AW, Gaser C (2008) Mapping the relationship between cortical convolution and intelligence: effects of gender. Cereb Cortex 18:2019-2026. CrossRef Medline

Mueller S, Wang D, Fox MD, Yeo BT, Sepulcre J, Sabuncu MR, Shafee R, Lu J, Liu H (2013) Individual variability in functional connectivity architecture of the human brain. Neuron 77:586-595. CrossRef Medline

Nie J, Li G, Wang L, Gilmore JH, Lin W, Shen D (2012) A computational growth model for measuring dynamic cortical development in the first year of life. Cereb Cortex 22:2272-2284. CrossRef Medline

Nie J, Li G, Shen D (2013a) Development of cortical anatomical properties from early childhood to early adulthood. Neuroimage 76:216-224. CrossRef Medline

Nie J, Li G, Wang L, Shi F, Lin W, Gilmore JH, Shen D (2013b) Longitudinal development of cortical thickness, folding, and fiber density networks in the first 2 years of life. Hum Brain Mapp. Advance online publication. Retrieved February 19, 2014. doi:10.1002/hbm.22432. CrossRef Medline

Ono M, Kubik S, Abernathey CD (1990) Atlas of the cerebral sulci. Stuttgart: G. Thieme.

Palaniyappan L, Liddle PF (2012) Aberrant cortical gyrification in schizophrenia: a surface-based morphometry study. J Psychiatry Neurosci 37: 399-406. CrossRef Medline

Petanjek Z, Judas M, Kostović I, Uylings HB (2008) Lifespan alterations of basal dendritic trees of pyramidal neurons in the human prefrontal cortex: a layer-specific pattern. Cereb Cortex 18:915-929. CrossRef Medline

Petanjek Z, Judaš M, Šimic G, Rasin MR, Uylings HB, Rakic P, Kostovic I (2011) Extraordinary neoteny of synaptic spines in the human prefrontal cortex. Proc Natl Acad Sci U S A 108:13281-13286. CrossRef Medline

Petrides M (2005) Lateral prefrontal cortex: architectonic and functional organization. Philos Trans R Soc Lond B Biol Sci 360:781-795. CrossRef Medline

Rakic P, Bourgeois JP, Goldman-Rakic PS (1994) Synaptic development of the cerebral cortex: implications for learning, memory, and mental illness. Prog Brain Res 102:227-243. CrossRef Medline

Raznahan A, Shaw P, Lalonde F, Stockman M, Wallace GL, Greenstein D, Clasen L, Gogtay N, Giedd JN (2011) How does your cortex grow? J Neurosci 31:7174-7177. CrossRef Medline

Rogers J, Kochunov P, Zilles K, Shelledy W, Lancaster J, Thompson P, Duggirala R, Blangero J, Fox PT, Glahn DC (2010) On the genetic architecture of cortical folding and brain volume in primates. Neuroimage 53: 1103-1108. CrossRef Medline

Schaer M, Cuadra MB, Tamarit L, Lazeyras F, Eliez S, Thiran JP (2008) A surface-based approach to quantify local cortical gyrification. IEEE Trans Med Imaging 27:161-170. CrossRef Medline

Schultz CC, Wagner G, Koch K, Gaser C, Roebel M, Schachtzabel C, Nenadic I, Reichenbach JR, Sauer H, Schlösser RG (2013) The visual cortex in schizophrenia: alterations of gyrification rather than cortical thickness-a combined cortical shape analysis. Brain Struct Funct 218:51-58. CrossRef Medline

Shaw P, Kabani NJ, Lerch JP, Eckstrand K, Lenroot R, Gogtay N, Greenstein D, Clasen L, Evans A, Rapoport JL, Giedd JN, Wise SP (2008) Neurodevelopmental trajectories of the human cerebral cortex. J Neurosci 28: 3586-3594. CrossRef Medline

Shaw P, Malek M, Watson B, Sharp W, Evans A, Greenstein D (2012) Development of cortical surface area and gyrification in attention-deficit/ hyperactivity disorder. Biol Psychiatry 72:191-197. CrossRef Medline

Shen D, Davatzikos C (2002) HAMMER: hierarchical attribute matching mechanism for elastic registration. IEEE Trans Med Imaging 21:14211439. CrossRef Medline

Shi F, Fan Y, Tang S, Gilmore JH, Lin W, Shen D (2010) Neonatal brain image segmentation in longitudinal MRI studies. Neuroimage 49:391400. CrossRef Medline

Shi F, Yap PT, Wu G, Jia H, Gilmore JH, Lin W, Shen D (2011) Infant brain atlases from neonates to 1- and 2-year-olds. PLoS One 6:e18746. CrossRef Medline

Shi F, Wang L, Dai Y, Gilmore JH, Lin W, Shen D (2012) LABEL: pediatric brain extraction using learning-based meta-algorithm. Neuroimage 62: 1975-1986. CrossRef Medline

Sled JG, Zijdenbos AP, Evans AC (1998) A nonparametric method for automatic correction of intensity nonuniformity in MRI data. IEEE Trans Med Imaging 17:87-97. CrossRef Medline

Smith SM, Nichols TE (2009) Threshold-free cluster enhancement: addressing problems of smoothing, threshold dependence and localisation in cluster inference. Neuroimage 44:83-98. CrossRef Medline

Su S, White T, Schmidt M, Kao CY, Sapiro G (2013) Geometric computation of human gyrification indexes from magnetic resonance images. Hum Brain Mapp 34:1230-1244. CrossRef Medline

Toro R, Perron M, Pike B, Richer L, Veillette S, Pausova Z, Paus T (2008) Brain size and folding of the human cerebral cortex. Cereb Cortex 18: 2352-2357. CrossRef Medline

Van Essen DC (1997) A tension-based theory of morphogenesis and compact wiring in the central nervous system. Nature 385:313-318. CrossRef Medline

Van Essen DC (2005) A population-average, landmark- and surface-based (PALS) atlas of human cerebral cortex. Neuroimage 28:635-662. CrossRef Medline

Van Essen DC, Drury HA (1997) Structural and functional analyses of human cerebral cortex using a surface-based atlas. J Neurosci 17:7079-7102. Medline

Wallace GL, Robustelli B, Dankner N, Kenworthy L, Giedd JN, Martin A (2013) Increased gyrification, but comparable surface area in adolescents with autism spectrum disorders. Brain 136:1956-1967. CrossRef Medline

Wang L, Shi F, Yap PT, Lin W, Gilmore JH, Shen D (2013) Longitudinally guided level sets for consistent tissue segmentation of neonates. Hum Brain Mapp 34:956-972. CrossRef Medline

Wang L, Shi F, Li G, Gao Y, Lin W, Gilmore JH, Shen D (2014) Segmentation of neonatal brain MR images using patch-driven level sets. Neuroimage 84:141-158. CrossRef Medline

White T, Su S, Schmidt M, Kao CY, Sapiro G (2010) The development of gyrification in childhood and adolescence. Brain Cogn 72:36-45. CrossRef Medline

Wood JN, Grafman J (2003) Human prefrontal cortex: processing and representational perspectives. Nat Rev Neurosci 4:139-147. CrossRef Medline

Worsley KJ, Taylor JE, Tomaiuolo F, Lerch J (2004) Unified univariate and multivariate random field theory. Neuroimage 23 [Suppl 1]:S189-S195. Medline

Wu G, Qi F, Shen D (2006) Learning-based deformable registration of MR brain images. IEEE Trans Med Imaging 25:1145-1157. CrossRef Medline

Xue Z, Shen D, Karacali B, Stern J, Rottenberg D, Davatzikos C (2006) Simulating deformations of MR brain images for validation of atlas-based segmentation and registration algorithms. Neuroimage 33:855-866. CrossRef Medline

Yap PT, Fan Y, Chen Y, Gilmore JH, Lin W, Shen D (2011) Development trends of white matter connectivity in the first years of life. PLoS One 6:e24678. CrossRef Medline

Yeo BT, Sabuncu MR, Vercauteren T, Ayache N, Fischl B, Golland P (2010) Spherical Demons: fast diffeomorphic landmark-free surface registration. IEEE Trans Med Imaging 29:650-668. CrossRef Medline

Zhu D, Li K, Guo L, Jiang X, Zhang T, Zhang D, Chen H, Deng F, Faraco C, Jin C, Wee CY, Yuan Y, Lv P, Yin Y, Hu X, Duan L, Hu X, Han J, Wang L, Shen D et al. (2013) DICCCOL: dense individualized and common connectivity-based cortical landmarks. Cereb Cortex 23:786-800. CrossRef Medline

Zilles K, Armstrong E, Schleicher A, Kretschmann HJ (1988) The human pattern of gyrification in the cerebral cortex. Anat Embryol (Berl) 179: 173-179. CrossRef Medline

Zilles K, Armstrong E, Moser KH, Schleicher A, Stephan H (1989) Gyrification in the cerebral cortex of primates. Brain Behav Evol 34:143-150. CrossRef Medline

Zilles K, Palomero-Gallagher N, Amunts K (2013) Development of cortical folding during evolution and ontogeny. Trends Neurosci 36:275-284. CrossRef Medline 